\title{
Advanced Energy Management Control for Energy Storage System
}

Link to publication record in Manchester Research Explorer

\section{Citation for published version (APA):}

Wu, D., Todd, R., \& Forsyth, A. (2014). Advanced Energy Management Control for Energy Storage System. In host publication

\section{Published in:}

host publication

\section{Citing this paper}

Please note that where the full-text provided on Manchester Research Explorer is the Author Accepted Manuscript or Proof version this may differ from the final Published version. If citing, it is advised that you check and use the publisher's definitive version.

\section{General rights}

Copyright and moral rights for the publications made accessible in the Research Explorer are retained by the authors and/or other copyright owners and it is a condition of accessing publications that users recognise and abide by the legal requirements associated with these rights.

\section{Takedown policy}

If you believe that this document breaches copyright please refer to the University of Manchester's Takedown Procedures [http://man.ac.uk/04Y6Bo] or contact uml.scholarlycommunications@manchester.ac.uk providing relevant details, so we can investigate your claim.

\section{OPEN ACCESS}


This paper was published at the IET Power Electronics, Machines and Drives (PEMD) Conference in April 2014, doi 10.1049/cp.2014.0443, and is available at:

http://ieeexplore.ieee.org/stamp/stamp.jsp?tp=\&arnumber=6836936

D. Wu, R. Todd, A.J. Forsyth, "Advanced energy management control for Energy Storage System," 7th IET International Conference on Power Electronics, Machines and Drives (PEMD), April 2014, doi: 10.1049/cp.2014.0443

(C) 2014 IET. Personal use of this material is permitted. Permission from the IET must be obtained for all other uses, in any current or future media, including reprinting/republishing this material for advertising or promotional purposes, creating new collective works, for resale or redistribution to servers or lists, or reuse of any copyrighted component of this work in other works. 


\title{
Advanced Energy Management Control for Energy Storage System
}

\author{
D. Wu, R. Todd, A. J. Forsyth \\ School of Electrical and Electronic Engineering, The University of Manchester, UK \\ ding.wu-2@postgrad.manchester.ac.uk
}

Keywords: Energy storage system, energy management, prioritised load, charge/discharge profiles, DC power network

\begin{abstract}
An energy management controller based on multiple charge/discharge profiles is proposed and analysed for an energy storage system. Each profile is designed to use the available energy more aggressively in different power regions, including the low or the high power regions, or both regions to minimise the rate-of-change of power source output. The performance of the energy storage system with the profiles is examined by simulation when connected to an aircraft 540V DC bus with a fault-tolerant starter/generator and high power, pulsed loads.
\end{abstract}

\section{Introduction}

The more-electric-aircraft (MEA) concept results in a significant increase in the number and power of electrical loads and sources connected to a single DC power distribution network. Many of the loads are direct replacements for existing non-electrically driven fuel pumps, environmental control compressors, actuators and avionic systems. This electrification of existing loads introduces more highly-dynamic, high-power loads to the network, creating energy management, power quality and network stability challenges due to the load characteristics, use of low input impedance input filters [1], and the constant power characteristics of most power electronic motor drives. The higher load capacity, coupled with the potential for rapid high power transients also results in more onerous demands on the gas-engine mounted generator(s), leading to excessive wear and reduced lifetime [2]. The rapid load changes on the generator will propagate to the gas-engine, which under certain load conditions may surge.

A candidate solution to the afore-mentioned energy management, power quality and stability challenges is the use of energy storage systems (ESSs). By absorbing and releasing energy at different times with very little energy loss, ESSs provide a mechanism to reconcile the instantaneous mismatch between load demands and source capacity/availability. Supercapacitor-based ESSs are attractive owing to their high power capacity [3], nearly unlimited charge/discharge cycles [4] and high cycle efficiency, above 95\% [3]. Designing the ESS for the maximum power network capacity often results in the ESS having a similar response over the full load range and so the ESS is often underutilised, meaning that although the ESS is limiting the effect of the load transients on the power source, the ESS could be controlled to offer a more gentle response. For example, during a flight period when the average load on the bus is low then only a small portion of the ESS energy is utilised, or if the network is only heavily loaded for short time periods then the ESS is only occasionally fully utilised.

The ESS in this work shields the power source from the instantaneous load transients on the DC bus, and through the use of charge/discharge profiles which target different load region(s), enables the rate-of-change in power source output to be minimised. The charge/discharge profiles enable the ESS to be more aggressively used over specific load ranges to minimise the load transients on the power source while better utilising the ESS energy.

Limiting the rate-of-change in source output power, to minimise wear thereby increasing the lifetime [2], can be achieved using an ESS with either a fixed rate limiter [6] set to the maximum permissible rate-of-change for the power source, or adding a low-pass [7], [8] or Kalman [9] filter element to the control. The rate limiter or filter cause the ESS to source or sink power during mismatches in source power and load demand, protecting the power source from the sudden load transients. A feature to all of these methods is that the ESS response follows a single pre-defined characteristic limiting the rate-of-change in power source output to a fixed maximum over the full load range. The techniques are unable to prioritise specific load ranges to use the ESS more effectively. Multiple pre-defined ESS state-ofcharge (SoC) profiles [10] have been proposed for a hybrid battery/supercapacitor system, however the objective in [10] was to charge/discharge the supercapacitor according to vehicle speed and battery depth-of-discharge, whereas in a MEA a key objective is to minimise the rate-of-change in power source output for specific load powers.

In the following sections a simple aircraft power network is described, together with an overview of the ESS control including the charge/discharge profiles. Simulation results, using experimentally validated models [11], [12], are then presented, enabling the ESS performance to be evaluated using typical aircraft load profiles. 


\section{System configuration}

A subset of the aircraft demonstrator facility [13] is shown in Figure 1. The system consists of a single power source, a $30 \mathrm{~kW}$ switched reluctance starter/generator [12] supplying the $540 \mathrm{~V}$ DC bus, an ESS (peak power $25 \mathrm{~kW}$ ) and multiple avionic and pulsed loads.

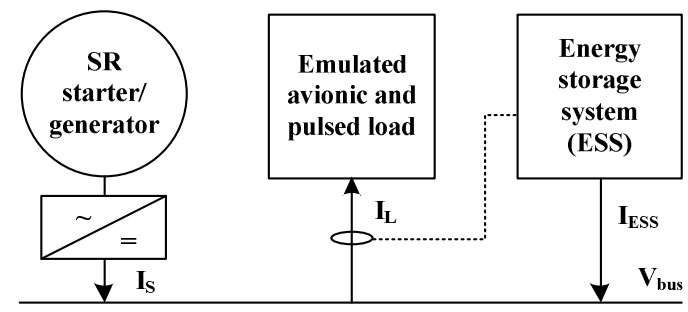

Figure 1. Overview of experimental test configuration.

The system in Figure 1 enables different load profiles to be imposed on the power network which must be managed by the ESS to limit the rate-of-change of generator power. Multiple load profiles are used to examine the performance of the advanced energy management control, including single load steps and a combined load, consisting of an avionic load and a pulsed load.

\section{ESS control and energy management profiles}

The ESS and associated control structure is shown in Figure 2, which takes the same form as that proposed in [11]. The ESS comprises a supercapacitor bank modelled with series and leakage resistances, $\mathrm{R}_{\mathrm{ESR}}, \mathrm{R}_{\mathrm{EPR}}$ and a capacitance $\mathrm{C}_{\mathrm{SC}}$, and a bi-directional DC/DC converter with a filter inductor $\mathrm{L}_{\mathrm{ESS}}$. Averaged modelling is used in the simulation and control design [11].

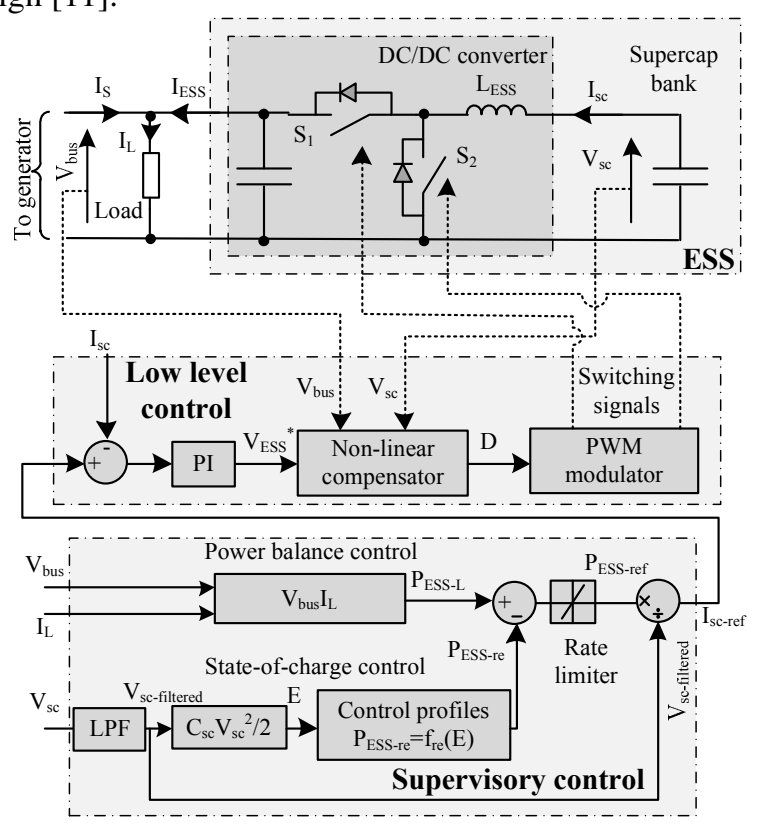

Figure 2. ESS and its control.

A cascaded control scheme is deployed, where the low level control regulates the supercapacitor current, $\mathrm{I}_{\mathrm{sc}}$, using a PI controller and a non-linear compensator [11] which transforms the converter into a first order system. The supervisory control determines $\mathrm{I}_{\text {sc-ref }}$ which is obtained from the power reference $P_{\text {ESS-ref }}$ divided by the filtered supercapacitor voltage. A low-pass filter has been applied to the measured $\mathrm{V}_{\mathrm{sc}}$ to remove the sudden step change which occurs when the load changes power causing the voltage drop across the supercapacitor $\mathrm{R}_{\mathrm{ESR}}$ to vary. The power reference $\mathrm{P}_{\mathrm{ESS}-\text { ref }}$ in Figure 2 consists of two components: a power balance control component $\mathrm{P}_{\text {ESS-L }}$ from the measured load power, and a state-of-charge control component $\mathrm{P}_{\mathrm{ESS}-\mathrm{re}}$ which varies much more slowly depending on the ESS energy E, as determined by the control profiles described in Section 3.1. A rate limit is applied to the sum of $\mathrm{P}_{\mathrm{ESS}-\mathrm{L}}$ and $\mathrm{P}_{\mathrm{ESS}-\mathrm{re}}$ to impose a fixed maximum permitted rate-of-change in power source output.

The ESS power will not be zero until $\mathrm{P}_{\mathrm{ESS}-\mathrm{L}}$ and $\mathrm{P}_{\mathrm{ESS}-\mathrm{re}}$ are equal, i.e., when the load power is equal to the recharge function $P_{L}=P_{E S S-L}=P_{E S S-r e}=f_{r e}(E)$. This gives a function that maps ESS energy with load power $\mathrm{P}_{\mathrm{L}},(1)$ :

$$
E=f\left(P_{L}\right)
$$

By using the inverse of (1), $\mathrm{f}_{\mathrm{re}}(\mathrm{E})$ in Figure 2, the energy within the ESS can be managed. However, this function can take various forms which results in different performance.

\subsection{ESS energy management profiles}

A common approach to manage ESS energy is that the energy level should be low when there is a possibility of returned or regenerated energy and the energy level should be high when the load level is low, i.e., the energy level E should be inversely correlated with $\mathrm{P}_{\mathrm{L}}$. Following this approach, five control profiles are proposed as shown in Figure 3. Both axes in Figure 3 are in per unit and vary from 0 to 1 . The per unit control profiles in Figure 3 can be scaled for a specific ESS and load provided that the maximum useable energy $E_{\max }$ and maximum load power $\mathrm{P}_{\mathrm{L}-\max }$ are known. In practice the zero usable energy condition would correspond to a minimum residual energy in the storage system which might be $20-25 \%$ of the maximum storage capacity for a supercapacitor bank. All the profiles except profile $\mathrm{K}$, are piecewise linear and the turning points are labelled in the figure. The profile $\mathrm{K}$ is taken from [11] exhibiting non-linearity. Alternative profiles are valid provided that they have the same starting and ending points, where at $(0,1)$, there is no load and full energy, and at $(1,0)$ there is zero useable energy and full load.

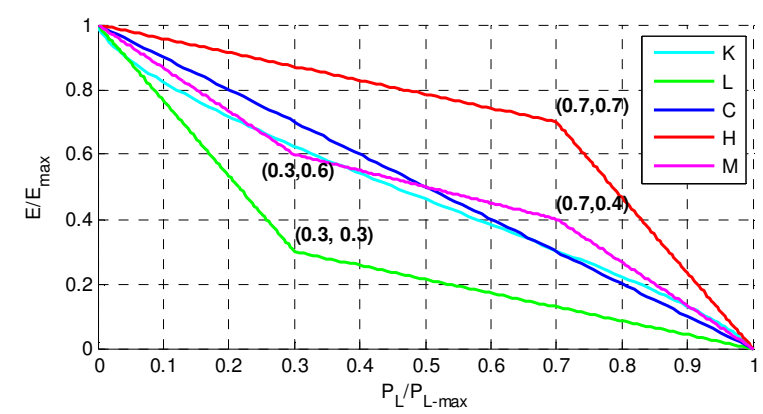

Figure 3. Generic control profiles. 
The energy usage from the ESS varies significantly between the individual profiles in Figure 3 resulting in different ratesof-change in generator power for a specific load power region. Profile L uses energy more aggressively in the low power region, profile $\mathrm{H}$ has higher energy usage in the high load region, profile $M$ is a blend of profile $L$ and $H$ and so is designed to give reasonably high energy usage during low and high power regions (at the expense of little energy available for medium load powers). The energy usage of profile $\mathrm{C}$ is constant across the full load range and profile $\mathrm{K}$ [11] is included for comparison. In the following sections, the performance of these profiles will be examined.

\section{Simulation results}

A SIMULINK simulation model is used to evaluate the performance of the system in Figure 1 for the ESS control profiles shown in Figure 3. A 30kW generator (SRSG) [12] is the main power source on the network, which regulates the DC-bus voltage to nominally $540 \mathrm{~V}$. A simple droop control element [13] is included in the generator control to manage the generator output power when multiple power sources are active. The ESS as discussed in Section 3 is active on the DCbus, together with a $25 \mathrm{~kW}$ avionic load and a $9 \mathrm{~kW}$ pulsed load, which are both modelled as constant power loads.

\subsection{Simulation configuration for the ESS}

The ESS supercapacitor bank is formed from three 48V $165 \mathrm{~F}$ modules (Maxwell BMOD0165), which enables an operating range from $60 \mathrm{~V}$ to $135 \mathrm{~V}$ and $0.4 \mathrm{MJ}$ of useable energy. The minimum supercapacitor voltage is restricted due to current limits in the converter and the achievable conversion ratio. The series $R_{E S R}$ and leakage $R_{E P R}$ resistance of the supercapacitor modules are $7.1 \mathrm{~m} \Omega$ and $10 \mathrm{k} \Omega$ respectively [9]. The converter filter inductor $\mathrm{L}_{\mathrm{ESS}}$ is $100 \mu \mathrm{H}$. The current control loop bandwidth is $8 \mathrm{kHz}$ [11]. The total capacitance on the $540 \mathrm{~V}$ DC distribution bus is $8 \mathrm{mF}$ [12]. Since a full charge or discharge cycle takes $16 \mathrm{~s}$ at maximum power of $25 \mathrm{~kW}$, the rate limiter has been set at $1.6 \mathrm{~kW} / \mathrm{s}$ and the LPF on supercapacitor voltage has a $1 \mathrm{~s}$ time constant which is significantly less than a full charge or discharge time.

Multiple recharge control profiles have been designed, as discussed in Section 3, which are converted into a $\mathrm{V}_{\mathrm{sc}}$ against $\mathrm{P}_{\mathrm{L}}$ map as shown in Figure 4 for the target system, where $\mathrm{V}_{\text {sc-max }}=135 \mathrm{~V}, \mathrm{~V}_{\text {sc-min }}=60 \mathrm{~V}$ and $\mathrm{P}_{\mathrm{L}-\max }=25 \mathrm{~kW}$. $\mathrm{V}_{\text {sc }}$ is used in Figure 4 as this is the measured system variable in Figure 2 for the test ESS.

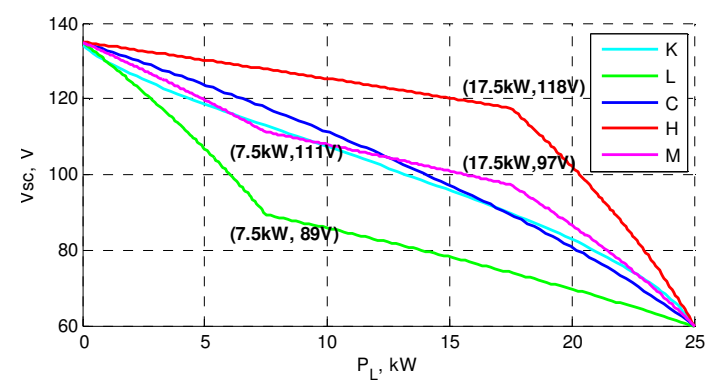

Figure 4. Control profiles for the supercapacitor ESS.

\subsection{Small and large load steps}

Simulation results for a small load step are shown in Figure 5, when the ESS is commanded using the profiles defined in Figure 4 . The $5 \mathrm{~kW}-7 \mathrm{~kW}$ load step occurs at $\mathrm{t}=10 \mathrm{~s}$ in Figure 5 and has a rise time of $10 \mathrm{~ms}$. In Figure 5, the top plot shows the load power, $\mathrm{P}_{\mathrm{L}}$, and generator power $\mathrm{P}_{\mathrm{S}}$, the second plot is the rate-of-change in generator power $\mathrm{dP}_{\mathrm{S}} / \mathrm{dt}$, the third plot is supercapacitor voltage $\mathrm{V}_{\mathrm{sc}}$, and the bottom plot is bus voltage Vus.

The general characteristics in Figure 5 correspond well with anticipated system behaviour for all profiles. For the $5 \mathrm{~kW}$ to $7 \mathrm{~kW}$ load step in Figure 5, which is in the low power region of the $25 \mathrm{~kW}$ system, profile L results in the gentlest generator response compared to the other profiles tested, confirming the profile design characteristics in Figure 4. The generator power response for profile $\mathrm{K}$ is similar to profile $\mathrm{C}$, since they have similar profiles as shown in Figure 4 . The bus voltage shows no significant transients or instability, and the steadystate supercapacitor values in Figure 5 are in good agreement with the theoretical profiles in Figure 4.
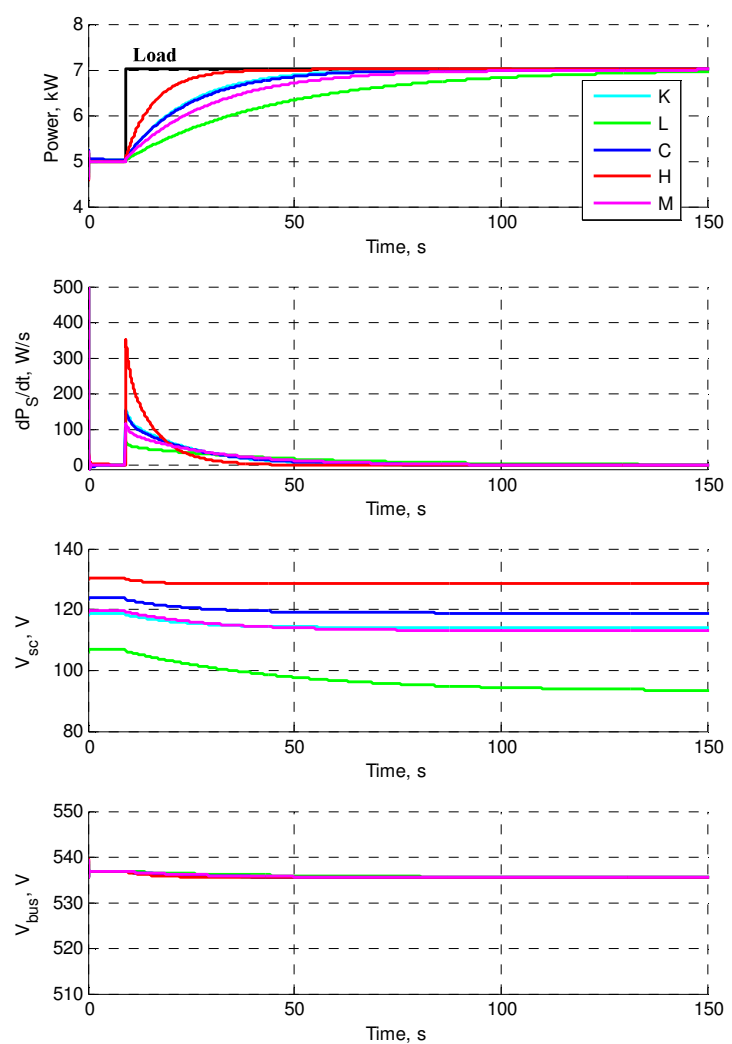

Figure 5. Small load step, $5 \mathrm{~kW}$ to $7 \mathrm{~kW}$ simulation results.

The maximum $\mathrm{dP}_{\mathrm{S}} / \mathrm{dt}$ experienced by the generator varies significantly between the profiles tested. Profile L has the lowest $\mathrm{dP}_{\mathrm{S}} / \mathrm{dt}$ of all profiles tested with a maximum $\mathrm{dP}_{\mathrm{S}} / \mathrm{dt}$ of $65 \mathrm{~W} / \mathrm{s}$. Profiles $\mathrm{C}$ and $\mathrm{K}$ have similar maximum $\mathrm{dP}_{\mathrm{S}} / \mathrm{dt}$ $(150 \mathrm{~W} / \mathrm{s})$ in response to the load change, which is slightly higher than the profile $\mathrm{M}$ maximum $\mathrm{dP}_{\mathrm{S}} / \mathrm{dt}$ of $115 \mathrm{~W} / \mathrm{s}$. In contrast, profile $\mathrm{H}$ has the largest $\mathrm{dP}_{\mathrm{S}} / \mathrm{dt}$ rate of $350 \mathrm{~W} / \mathrm{s}$; 
nevertheless, the generator response is still gentler than if the ESS is offline.

A full power load step is shown in Figure 6. Figure 6.a shows results when the rate limiter on PESS-re in Figure 2 is disabled, whereas Figure $6 . \mathrm{b}$ shows plots when a $1.6 \mathrm{~kW} / \mathrm{s}$ rate limit is applied. Since the full load of $25 \mathrm{~kW}$ is applied, all the profiles have the same target supercapacitor voltage of $60 \mathrm{~V}$, which is confirmed by the simulation results shown in Figure 6 .
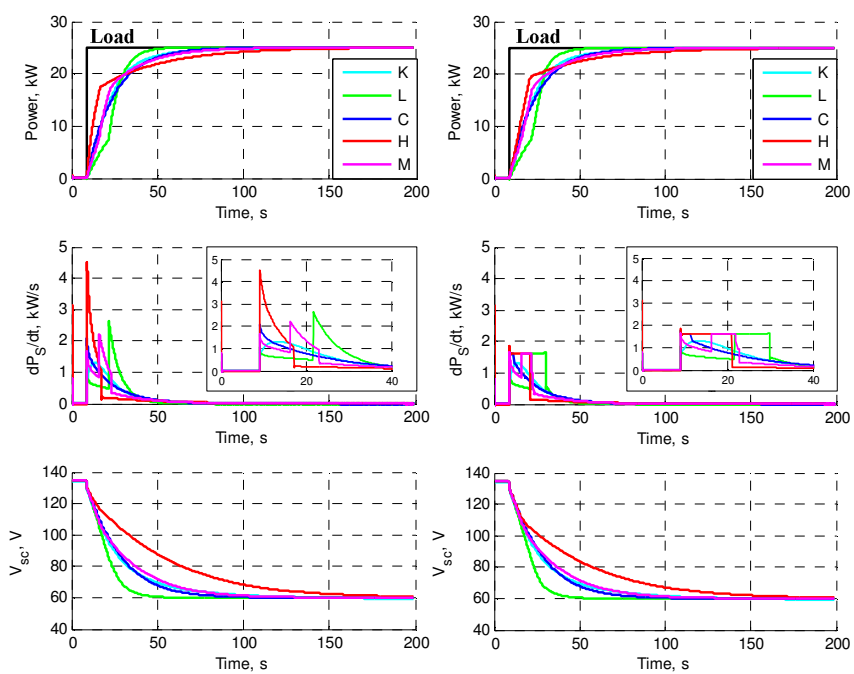

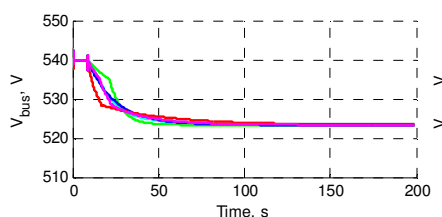

a. no rate limiter.

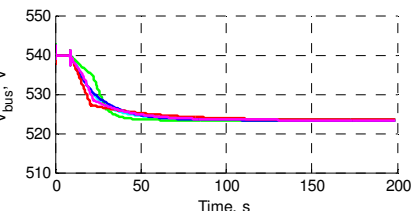

b. $1.6 \mathrm{~kW} / \mathrm{s}$ rate limit.
Figure 6. Large load step, zero to $25 \mathrm{~kW}$, simulation results.

However, the generator power during the transition varies significantly among the different profiles. Taking profile $\mathrm{L}$ as an example, the generator power initially has a low $\mathrm{dP}_{\mathrm{S}} / \mathrm{dt}$ compared to the other profiles until $7.5 \mathrm{~kW}$ after which the $\mathrm{dP}_{\mathrm{S}} / \mathrm{dt}$ rises significantly. The transition power in generator response matches the profile defined in Figure 4 , since $7.5 \mathrm{~kW}$ is where the gradient of the profile $\mathrm{L}$ changes as the supercapacitor voltage drops. The more gradual gradient of the profile in the region when $P_{L}>7.5 \mathrm{~kW}$ causes less energy to be used which as a consequence forces the generator output power to increase more rapidly to meet the load power. Profiles $\mathrm{H}$ and $\mathrm{M}$ in Figure 6 also exhibit this behaviour, with the profile transition occurring at $17.5 \mathrm{~kW}$. Correspondingly, the $\mathrm{dP}_{\mathrm{S}} / \mathrm{dt}$ from profiles $\mathrm{H}, \mathrm{M}$ and $\mathrm{L}$ all clearly show these two different regions. The generator power response when profile $\mathrm{K}$ is used initially has a higher $\mathrm{dP}_{\mathrm{S}} / \mathrm{dt}$ which slowly reduces to zero after $75 \mathrm{~s}$, and is again similar to profile $\mathrm{C}$.

Although the generator power rate-of-change in Figure 6.a is gentler than if the ESS is offline, the high $\mathrm{dP}_{\mathrm{S}} / \mathrm{dt}$ may still result in wear damage. A rate limit of $1.6 \mathrm{~kW} / \mathrm{s}$ has been added to the $\mathrm{P}_{\mathrm{ESS}-\mathrm{re}}$ output to limit the maximum rate-ofchange in generator power. The changes in simulation results with the limit can be clearly observed in the second row of Figure $6 . \mathrm{b}$, where the $\mathrm{dP}_{\mathrm{S}} / \mathrm{dt}$ is clamped at $1.6 \mathrm{~kW} / \mathrm{s}$. However, the main features of the different profiles still remain as in Figure 6.a.

The bus voltage is generally stable in Figure 6, although a slight transient of $\pm 2 \mathrm{~V}$ is apparent when the load changes power. The longer term variation in bus voltage that is evident in Figure 6 is due to the generator droop controller [13] which linearly reduces the reference DC bus voltage from $540 \mathrm{~V}$ to $520 \mathrm{~V}$ if the generator is loaded at $30 \mathrm{~kW}$.

\subsection{Combined avionic and pulsed load}

Figure 7 shows two separate load profiles, an avionic base load and a pulsed load, which are combined to load the network. The simplified avionic load profile draws $1 \mathrm{~kW}$ for $100 \mathrm{~s}$ and then steps to $16 \mathrm{~kW}$ with a $10 \mathrm{~ms}$ rise time for a further 100s. Throughout the avionic profile, a $9 \mathrm{~kW} 0.5 \mathrm{~Hz}$ pulsed load with a 0.5 duty-cycle is active.

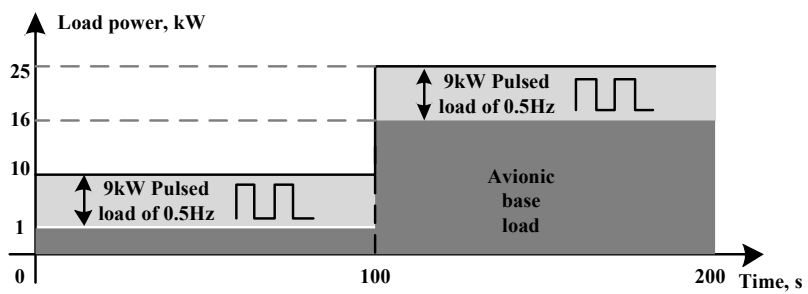

Figure 7. Combined avionic and pulsed load profile.

The simulation results for the combined avionic and pulsed load test are shown in Figure 8. The left hand plots in Figure 8 show the full simulation with the right hand plots showing short time periods for the steady-state behaviour of the system during the low power and high power avionic load periods.
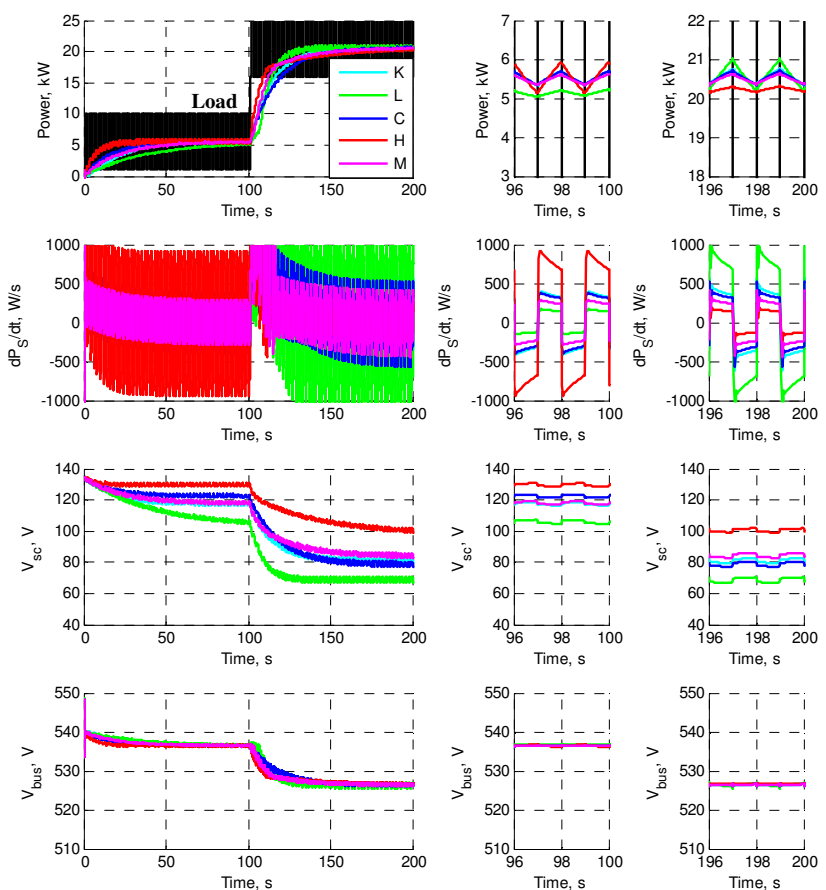

Figure 8. Combined avionic and pulsed load simulation results. 
The supercapacitor voltage is initialised at $135 \mathrm{~V}$, which, due to the initial $1 \mathrm{~kW}$ base-load with the $9 \mathrm{~kW} 0.5 \mathrm{~Hz}$ pulsed load is incorrect for all profiles from Figure 4 and so the ESS control must rebalance the supercapacitor voltage to the $5.5 \mathrm{~kW}$ average load value. The ESS rebalances, achieving a steady-state supercapacitor voltage in Figure 8 consistent with Figure 4, after approximately 60 s for all profiles with the exception of profile $\mathrm{L}$ since a lower supercapacitor voltage is targeted for profile $\mathrm{L}$ and this therefore takes a longer time to achieve. The bus voltage is stable in Figure 8 and varies slightly with load power due to the generator's droop control [13] which is comfortably within the limits defined in MIL-Std704F.

The generator power, top plots in Figure 8, is effectively shielded from the large pulsed load for all profiles in Figure 4 as the ESS is supplying the pulsed component of the load. The reduced rate-of-change in generator power compared to the load power is evident in Figure 8, both after the large power step at $100 \mathrm{~s}$ and, in the right hand plots, the generator experiences a small ripple power (less than $1 \mathrm{~kW}$ ) in response to the $9 \mathrm{~kW}$ pulsed load.

The generator response using profile L consumes a significant portion of the available stored energy in the first 100s (low load region) and so the generator is loaded more gradually, while profile $\mathrm{H}$ only uses a small amount of energy, and so the generator power rises more rapidly reaching a steady-state condition within 20s. The different rates-of-change in generator power before and after the power transition $(7.5 \mathrm{~kW}$ and $17.5 \mathrm{~kW}$ ) in Figure 4 is again apparent in the results from profiles $\mathrm{H}$ and $\mathrm{M}$ after the avionic load step at $\mathrm{t}=100 \mathrm{~s}$. The transition in profile $\mathrm{L}$ is less visible since the initial load power is similar to the $7.5 \mathrm{~kW}$ transition power.

The ripples in generator power also reflect whether the ESS uses or stores energy more heavily. Profile L offers the smallest ripple in $\mathrm{P}_{\mathrm{S}}$ and lowest $\mathrm{dP}_{\mathrm{S}} / \mathrm{dt}$ in the low load region, though this is at the expense of high energy usage in the region. As a result only a small amount of energy remains for use in the high power region, resulting in profile $L$ having the highest $\mathrm{dP}_{\mathrm{S}} / \mathrm{dt}$ at heavy loads. Profile $\mathrm{H}$ demonstrates the opposite behaviour. Profile $\mathrm{C}$ has identical $\mathrm{dP}_{\mathrm{S}} / \mathrm{dt}$ in both the high and low load regions. Profile $M$ has a similar $\mathrm{dP}_{S} / \mathrm{dt}$ to profile $\mathrm{L}$ in the low load region and a similar $\mathrm{dP}_{\mathrm{S}} / \mathrm{dt}$ to profile $\mathrm{H}$ in the high power region, confirming the design in Figure 4. For the combined avionic and pulsed load profile M, offers the best overall performance in terms of enabling the lowest average $\mathrm{dP}_{\mathrm{S}} / \mathrm{dt}$ across the full load profile.

\section{Conclusion}

An advanced energy management control consisting of several ESS charge/discharge profiles, each designed to use the available energy more aggressively in specific load region(s), has been shown to be effective in limiting the rateof-change in main power source output in the targeted load range(s). The mixed profile $M$, which more heavily used the ESS energy in both the low and high load power range at the expense of light energy usage at medium load levels, offered the most gentle power source response overall for all of the load profiles considered. Considering the simple load steps, profile L offered the gentlest generator response for the small load step and profile $\mathrm{H}$ enabled the gentlest generator power response for the high load step, however, as these profiles focus on a single load range, neither profile offers good overall performance for the combined avionic and pulsed load.

The profiles considered each result in more aggressive operation of the ESS at different load levels and give an insight into choosing a suitable ESS charge/recharge function depending on the expected load conditions. If knowledge is available of the expected loads then the ESS charge/discharge profiles may be modified online to best utilise the ESS energy at all times. The $\mathrm{dP}_{\mathrm{S}} / \mathrm{dt}$ value gives a guide in choosing the ESS capacity based on the need to satisfy a limit on the rateof-change of power drawn from the main source to avoid its sub-optimal operation or malfunction. Future work in this area includes experimental validation of the different charge/discharge profiles.

\section{Acknowledgements}

The authors would like to thank Rolls-Royce plc for supporting this research through the UTC in Electrical Power Conversion at The University of Manchester.

\section{References}

[1] J. A. Weimer, "Electrical power technology for the more electric aircraft," IEEE Digital Avionics Systems Conference, 1993, pp. 445-450.

[2] H. Zhang, C. Saudemont, B. Robyns, and M. Petit, "Comparison of technical features between a More Electric Aircraft and a Hybrid Electric Vehicle," IEEE Vehicle Power and Propulsion Conference (VPPC), 2008, pp. 1-6.

[3] P. V. D. Bossche, "Models of energy sources for EV and HEV: fuel cells, batteries, ultracapacitors, flywheels and engine-generators," Journal of Power Sources, 2004.

[4] European commision, "Energy Storage - A Key Technology for Decentralized Power, Power Quality and Clean Transport," Office for Official Publications of the European Communities Luxembourg, 2001.

[5] S. M. Lukic, C. Jian, R. C. Bansal, F. Rodriguez, and A. Emadi, "Energy Storage Systems for Automotive Applications," IEEE Transactions on Industrial Electronics, vol. 55, 2008, pp. 2258-2267.

[6] P. Thounthong, S. Rael, and B. Davat, "Control Strategy of Fuel Cell and Supercapacitors Association for a Distributed Generation System," IEEE Transactions on Industrial Electronics, vol. 54, 2007, pp. 3225-3233.

[7] F. S. Garcia, A. A. Ferreira, and J. A. Pomilio, "Control Strategy for Battery-Ultracapacitor Hybrid Energy Storage System," Twenty-Fourth Annual IEEE Applied Power Electronics Conference and Exposition, 2009, pp. 826-832. 
[8] J. M. A. Curti, X. Huang, R. Minaki, and Y. Hori, "A simplified power management strategy for a supercapacitor/battery Hybrid Energy Storage System using the Half-Controlled Converter," 38th Annual Conference on IEEE Industrial Electronics Society (IECON), 2012, pp. 4006-4011.

[9] L. Battistelli, M. Fantauzzi, D. Iannuzzi, and D. Lauria, "Energy management of electrified mass transit systems with Energy Storage devices," International Symposium on Power Electronics, Electrical Drives, Automation and Motion (SPEEDAM), 2012, pp. 1172-1177.

[10] J. Dixon, I. Nakashima, E. F. Arcos, and M. Ortuzar, "Electric Vehicle Using a Combination of Ultracapacitors and ZEBRA Battery," IEEE Transactions on Industrial Electronics, vol. 57, 2010, pp. 943-949.

[11] R. Todd, D. Wu, J. A. dos Santos Girio, M. Poucand, and A. J. Forsyth, "Supercapacitor-based energy management for future aircraft systems," Twenty-Fifth Annual IEEE Applied Power Electronics Conference and Exposition (APEC), 2010, pp. 1306-1312.

[12] V. Valdivia, R. Todd, F. Bryan, A. Barrado, A. Lazaro, A. J. Forsyth, "Behavioural Modelling of a Switched Reluctance Generator for Aircraft Power Systems," IEEE Transactions on Industrial Electronics, vol. 61, issue 6, 2014, pp. 2690-2699.

[13] R. Todd, A.J. Forsyth, "HIL Emulation of All-Electric UAV Power Systems," IEEE Energy Conversion Congress and Exposition (ECCE), 2009, pp. 411-416. 